\title{
LA ÉTICA DE LA ALTERIDAD DE LÉVINAS COMO ELEMENTO IMPORTANTE EN EL CONOCIMIENTO DE LA FORMACIÓN ÉTICA EN LA EDUCACIÓN 1
}

(Recibido: Julio 3 de 2012 Aprobado: Agosto 14 de 2012)

Joe Breiner Duarte Zúñiga²

\section{Resumen}

El presente trabajo tiene como objetivo comprender de qué manera la ética de la alteridad de Lévinas aporta al conocimiento de la formación ética en la educación a través de un estudio teórico, en base a un análisis documental. Por ello, en un primer momento, se estudia el significado de la categoría alteridad como fundamento de la ética de Lévinas y se comprende por qué es importante la teoría ética de Lévinas entre las diversas teorías éticas actuales. En un segundo momento, se analiza qué importancia tiene el conocimiento de la teoría ética de la alteridad de Lévinas en la formación ética en la educación. Además se reflexiona si la ética de la alteridad de Lévinas contribuye para que el discurso ético en las comunidades educativas no sea vacío y de relleno, y, al contrario dé sentido a la construcción del ser humano y de la convivencia.

Por lo tanto el tema de investigación es el estudio de "la ética de la alteridad de Lévinas como elemento importante en el conocimiento de la formación ética en la educación". Es una temática determinada dentro del campo de trabajo teórico. Dentro de ese criterio teórico el contenido del tema que se estudia pertenece al área de conocimiento de la filosofía en relación con la educación. Así que, se hace un estudio a partir de un tema teórico con un enfoque filosófico y pedagógico.

\section{Palabras clave}

alteridad, ética, formación integral, hospitalidad, educación, inclusión

\section{“THE STUDY OF LEVINAS'S ALTERITY ETHIES AS AN IMPORTANT ELEMENT TO THE KNOWLEDGE IN ETHIGS FORMATION THROUGH EDUGATION"}

\section{Alostract}

This document aims at understanding in which way Lévinas' alterity theory contributes to the knowledge of the ethics education in education through a theoretical study, based on a deep research analysis. Thus it first studies the concept of alterity as a foundation of levinas's ethics to understand why this theory is so important among the various ethical theories. Secondly, it analyses the importance of the knowledge of this theory over the ethic training in education. Besides, it reflects about whether Levinas' alterity ethics theory contributes to the ethical speech in schools being less empty and superficial and instead making sense of the construction of the human being and cohabitation.

Therefore, the theme of this research is "the study of Levinas's alterity ethics as an important element to the knowledge in ethics training through education", a specific subject of the theoretical work field. According to that, this research belongs to the knowledge of philosophy related to education. This work starts from a theoretical subject with a philosophical and pedagogical approach.

\section{Key words}

Alterity, ethics, comprehensive formation, hospitality, education, inclusion criteria.

\footnotetext{
1 El presente artículo es producto de la investigación en el marco del proyecto "La ética de la alteridad de Lévinas como elemento importante en el conocimiento de la formación ética en la educación". Licenciatura en Filosofía y Ética y Valores humanos. VUAD-USTA. Bucaramanga.
}

2 Licenciado en Filosofía y Ética y Valores humanos. VUAD-USTA. Profesional en teología-ITESP. Sao Paulo (Brasil), 2007. joebrer@yahoo.com 


\section{Introducción}

No es posible entender un texto sin su contexto. Sin contexto no puede haber ni significado ni comprensión. Algunas cuestiones de las aquí expuestas responden al actual debate planteado entre los pedagogos sobre modelos (paradigmas) en educación, y específicamente en educación moral. Puede afirmarse que la discusión es muy abierta, hay varios enfoques que se hacen presentes en la investigación pedagógica y en las propuestas educativas (Ortega, 2011). La cuestión de fondo que se desarrolla en este trabajo se plasma en varios interrogantes, que son de motivación personal para escoger este tema de investigación: ¿Qué discurso o que ética está siendo teorizada en las comunidades educativas? ¿El discurso ético en la práctica educativa promueve el desarrollo integral? ¿La formación ética en las comunidades educativas es sólo un discurso vacio y de relleno o de búsqueda de sentido que construya la convivencia? ¿Qué sentido tiene realmente formar en valores a partir de la ética?

La respuesta que se da a estas preguntas condiciona toda la actividad. Se ha investigado mucho sobre las variables que influyen en los procesos de enseñanza-aprendizaje, pero se olvida que la percepción que el profesor tiene de su relación de educador con el educando, su actitud ante él es una variable decisiva en el proceso educativo, si pretende hacer "algo más" que transmitir conocimientos y enseñar destrezas o habilidades (Ortega, 2011).

La propuesta en la presente investigación es que la relación que se establece entre docente y estudiante, en el proceso de enseñanza-aprendizaje, debe ser una relación ética que se traduce en una actitud de acogida y un compromiso con el educando, es decir, hacerse cargo de él. Para el presente texto el investigador propone la categoría alteridad como fundamento de esa relación ética, a par- tir de Lévinas. Pues se puede decir que la educación moral se encuentra con la teoría ética levinasiana,

"que halla en el reconocimiento del otro su punto de partida, lo que lleva a situar, por coherencia, un nuevo modelo de educación moral, la de la alteridad" (Ortega R, 2011).

En el marco de esta propuesta, se trabaja desde el campo de la filosofía, más exactamente desde la filosofía moral, y se busca comprender, ¿De qué manera la ética de la alteridad de Lévinas aporta al conocimiento de la formación ética en la educación? El problema de investigación origina dos objetivos: en primer lugar conocer el significado de la categoría alteridad como fundamento de la ética de Lévinas, en segundo lugar, analizar qué importancia tiene el conocimiento de la teoría ética de la alteridad de Lévinas en la formación ética en la educación. Además reflexionar si la ética de la alteridad de Lévinas contribuye para que el discurso ético en las comunidades educativas no sea vacio y de relleno, $y$, al contrario dé sentido a la construcción del ser humano y de la convivencia.

Por lo tanto, es un tema determinado dentro del campo de trabajo teórico y con un enfoque filosófico, pero que busca dar aportes a la pedagogía desde la reflexión. Por eso en el desarrollo del trabajo se trabaja desde el análisis e interpretación de los textos, relacionados con la ética de la alteridad de Lévinas y de su relación con la formación ética en la educación, construyendo así el marco de referencia teórica.

La información se recopiló mediante diferentes técnicas y recursos propios de la investigación cualitativa como la revisión bibliográfica, y la técnica de investigación documental. A partir de este procedimiento se sistematizan y se analizan los datos teóricos acerca de la información, y de esta manera obtener 
los resultados, conclusiones y algunas recomendaciones.

\section{Justificación}

Es común escuchar en muchas instituciones educativas en Colombia la preocupación por una educación que busque la formación ética y la convivencia ciudadana de los estudiantes, esto es apoyado por el proyecto de formación que lidera el Ministerio de Educación, y en el marco de la Ley 115 de 1994, la Ley General de Educación que busca, no meramente, la capacitación intelectual sino el desarrollo integral y ético del estudiante con todas sus dimensiones.

El objeto de la Ley 115, confirma este quehacer educativo: "La educación es un proceso de formación permanente, personal, cultural y social que se fundamenta en una concepción integral de la persona humana, de su dignidad, de sus derechos y de sus deberes." (Ley 115, Art. I).

También el primero de los fines de la educación del artículo 5, en conformidad del artículo 67 de la Constitución Política de Colombia, sigue esta misma línea de pensamiento y de acción educativa, que pretende:

“El pleno desarrollo de la personalidad sin más limitaciones que las que le imponen los derechos de los demás y el orden jurídico, dentro de un proceso de formación integral, física, psíquica, intelectual, moral, espiritual, social, afectiva, ética, cívica y demás valores humanos." (CPC, Art. 67).

Por lo tanto es pertinente que desde la formación profesional en la educación, se indague por la importancia y la significación de la formación ética en la práctica educativa. El campo de la ética o filosofía moral, como discurso filosófico contribuye a esa indagación, de la misma manera, como lo hace la pedagogía como discurso de las ciencias sociales.
En este caso, la ética de la alteridad de Lévinas puede ser significativa, como teoría que puede fundamentar la formación ética de los estudiantes en las comunidades educativas. La utilidad e interés social de este estudio radica en que el pensamiento de Lévinas poco se ha abordado en perspectiva educativa en Colombia, lo que se podría convertir en una novedad. Además que el pensamiento levinasiano, es de alcance universal y de aplicabilidad en el campo del conocimiento de las ciencias sociales y de la educación.

Al mismo tiempo, la relación que se hace de la ética de la alteridad de Lévinas con la formación ética en la educación es un buen intento de fusionar horizontes del vasto conocimiento de la actualidad con el propósito de aportar teóricamente a una práctica educativa que busque formar personas integrales y ciudadanas para un mejor desarrollo moral de la sociedad.

Finalmente es indispensable decir que este tema de investigación va en concordancia con el eje de investigación en Filosofía de la cultura y Educación Ético-Política: desarrollo humano integral y convivencia ciudadana, propuesta por la facultad de educación.

\section{Marco de referencia teórica}

\subsection{Antecedentes de investiga- ción}

A nivel internacional y específicamente latinoamericano, cabe resaltar los varios trabajos monográficos que hacen parte del CEBEL, Centro Brasilero de Estudios sobre el pensamiento de Emmanuel Lévinas, adscrito a la PUCRS de Porto Alegre, Brasil. En estas investigaciones monográficas aparecen invaluables análisis para conocer el significado de la categoría alteridad como fundamento de 
la ética de Lévinas ${ }^{3}$ y comprender porque es importante la teoría ética de Lévinas entre las diversas teorías éticas actuales.

Una primera referencia para el estudio de la alteridad en Lévinas, es el trabajo de Tiegue Vieira Rodríguez (2007), titulado "a categoría da alteridade: uma análise da obra totalidade e infinito, de Emmanuel Lévinas", monografía presentada en la PUCRS de Porto Alegre (Brasil). El texto tiene por objetivo hacer un análisis de la obra Totalidad e Infinito, de Emmanuel Lévinas, haciendo énfasis en la categoría de la "alteridad". El hilo conductor de este proyecto se concentra en la posibilidad de poder encontrar el Otro en su alteridad. Como problema general de investigación,

3 Dado que el pensamiento de Emmanuel Lévinas es la fundamentación teórica de esta investigación es necesario reseñar una pequeña biografía del pesador. Lévinas nace en Kaunas, Lituania, en la confluencia del Nieven y el Neris, frontera entre Letonia y Rusia. Nace el 30 de diciembre de 1906 según el calendario gregoriano. Fallece el 25 de diciembre de 1995 en Francia. Su papá Yehiel Lévinas y su mamá Dvora Gurvitch. Tiene dos hermanos: Boris y Aminadab. Su familia es judía tradicionalista practicante. Lévinas vive una infancia feliz, en una familia medio acomodada, sin experimentar el antisemitismo. Llega a Estraburgo en 1923, la ciudad francesa más cercana de Lituania. Estudia francés y filosofía. Su atracción filosófica se la debe a los escritores rusos Pushkin, Lérmontov, Dostoievski y Tolstoi. Influyeron en él sus maestros de Estrasburgo y se inspirará en Henri Bergson y Edmund Husserl. En búsqueda de Husserl se encontrará con Martín Heidegger. Tiene como amigo de juventud al literato Maurice Blanchot, que le hace leer a Proust y Valery y desarrollarán una complicidad intelectual. Hacia 1935 Lévinas descubre al filósofo judío alemán Franz Rosenzweig leyendo su obra "La estrella de la redención". En 1928-1929 asiste en Friburgo a los cursos impartidos por Husserl, se familiariza con la fenomenología, que marcará su pensamiento y método, en 1930 presenta su tesis "La theorie de I' intuition dans la phénoménologie de Husserl". En el año 1940 durante la segunda guerra mundial, es hecho prisionero, permaneciendo durante toda la guerra en un campo de concentración en Hannover, Alemania. Su condición de militar francés lo salva del trato que recibieron otros judíos. Durante ese período prácticamente toda su familia que había quedado en Lituania es masacrada por los nazis. Su esposa y su hija se salvan al quedar en un monasterio católico en Orleáns. De la experiencia de guerra Lévinas concluye que lo existente, que da sentido a los entes en el mundo, produce una impersonalidad árida, neutra, que sólo podría ser superada en el ser-para-el-otro, como momento ético de respeto a la Alteridad. Pese a no ser teólogo, Lévinas encontró en el judaísmo una fuente de inspiración para su reflexión. Para él, el judaísmo es una religión fundamentalmente ética. Sus dos principales obras fueron: Totalidad e infinito (1961) y De otro modo de ser o más allá de la esencia (1974). En: GARCIA, Mario. Ética filosófica de Emmanuel Lévinas en obra Totalidad e infinito. Recuperado el 23 de mayo de 2011. Disponible en: http://www. monografias.com/trabajos81/etica-filosofica-emmanuel-levinasobra-totalidad-e-infinito/etica-filosofica-emmanuel-levinas-obratotalidad-e-infinito.shtml. se tiene dos cuestiones: a) ¿por qué no se puede objetivar el Otro? b) ¿cuál es la posibilidad de pensar el Otro en su "Alteridad" absoluta? (cfr. Vieira, 2007, p. 7). El autor en las conclusiones responde que:

al pensar las cuestiones se puede percibir que están íntimamente ligadas, pues pensar el otro en su diferencia absoluta ya es, de cierto modo, asumir la imposibilidad de objetivar el otro, es decir, para sustentar la no objetivización del otro es necesario que haya una alteridad absoluta, que siempre se escapa al yo (Vieira, 2007,97).

Un segundo estudio sobre la ética de la alteridad de Lévinas es el trabajo monográfico de Luciano Costa Santos (2007), titulado "o sujeito é de sangue e carne: a sensibilidade como paradigma ético em emmanuel levinas" presentado en la PUCRS de porto Alegre (Brasil). El autor en su investigación intenta demostrar y profundizar:

"el sentido ético de la subjetividad en cuanto responsabilidad por el otro o uno-para-el-otro, mostrando que el ser humano se abre con la posibilidad extraordinaria de que la alteridad del Otro venga a contar para el sujeto antes que su propia identidad para sí mismo" (Costa, $2007,6)$.

A nivel nacional un estudio que hace referencia a la comprensión de la importancia de la teoría ética de Lévinas entre las diversas teorías éticas actuales es el de Jonathan Alexander Castelblanco Morales (2009), quien realiza un trabajo monográfico titulado "hacia otra ética inclusiva del otro excluido: la alternativa levinasiana por lo humano", trabajo que es presentado en la Pontificia Universidad Javeriana de Bogotá (Colombia). En este trabajo, Jonathan A. Castelblanco, hace un interesante análisis hermenéutico sobre la ética de la alteridad de Lévinas bajo la categoría del Otro como excluido. EI otro que ha sido excluido por la primacía 
de la ontología como filosofía primera, del anti humanismo que ha diseminado el ser humano moderno por su subjetivismo egoísta y totalitarista. Para ello aborda el estudio de la alteridad de Lévinas bajo la clave de interpretación de la inclusión, es decir, la ética inclusiva del otro excluido, y así buscar un autentico humanismo.

A nivel local, un estudio que hace referencia a la ética de la alteridad de Lévinas es el trabajo de investigación que se ha hecho en la Universidad Industrial de Santander (UIS), (Bucaramanga). Se trata del texto de Jazmín Riatiga Morales (2008) "El reconocimiento de la alteridad como apertura hacia el otro en la experiencia humana del conflicto, según Emmanuel Lévinas". Si bien el trabajo está enfocado hacia el conflicto humano, por su teorización de la apertura hacia el otro, trabaja el concepto de alteridad. El concepto de alteridad de Lévinas es leído por Jazmín Riatiga, como el reconocimiento del Otro en su total diferencia, en medio del conflicto que hay en el encuentro de los seres humanos, y que reconocer la diferencia del totalmente otro conllevaría a evitar la violencia y cultivar una cultura de la buena convivencia, lo que evitaría la violencia. La autora, hace uso del pensamiento de Lévinas por considerarlo el mejor abordaje sistemático filosófico acerca de la comprensión de la alteridad.

De las investigaciones halladas a nivel internacional, nacional y local, casi no discursan respecto del problema planteado de comprender la teoría ética de la alteridad de Lévinas en relación a la educación, aún así son valiosas sus contribuciones para conocer el significado de la categoría de la alteridad como fundamento de la ética de Lévinas, y comprender porque es importante la teoría ética de Lévinas entre las diversas teorías éticas actuales. Estos antecedentes se complementan con los aportes del marco de fundamentación teórica y conceptual, y, que hace que se analice qué importancia tiene el conoci- miento de la teoría ética de la alteridad de Lévinas en la formación ética en la educación y a reflexionar si la ética de la alteridad de Lévinas contribuye para que el discurso ético en las comunidades educativas no sea vacio y de relleno, y, al contrario dé sentido a la construcción del ser humano y de la convivencia.

\subsection{Fundamentación Teórica}

Por el enfoque teórico de la investigación, el universo de la fundamentación teórica fue explorar algunos capítulos de las dos obras magnas de Emanuel Lévinas, a saber, Totalidad e Infinito, y, De otro modo que ser o más allá de la esencia. Como obra de apoyo y de análisis, se trabajó el libro Emmanuel Lévinas, la filosofía como ética, coordinado por Andrés Alonso Martos. Ésta obra fue fruto del Congreso Internacional, sobre el pensamiento de Emmanuel Lévinas, en el año 2006, organizado por la universidad de Valencia y el Museo Valenciano de la Ilustración y de la Modernidad (MuVIM) en España. Es una obra de apoyo importante para comprender el pensamiento levinasiano. También los estudios del CEBEL ya reseñados encima, ayudaron a fundamentar este trabajo.

\subsubsection{La revelación del rostro del otro: posibilidad de la dimensión ética}

Para Emmanuel Lévinas, la ética de la alteridad, es posible cuando hay un reconocimiento del rostro del otro, esto es, hacerse responsable del otro antes de cualquier conceptualización, es aprehender el sentido ético del rostro del otro. El rostro del otro nos llama, nos desafía y nos invita. La ética de la alteridad en el rostro del otro revela su infinitud. Esta ética rompe paradigmas tradicionales establecidos por otras éticas. Lo que identifica al otro es su rostro, y es a menudo en el rostro del otro que encuentro $\mathrm{mi}$ propia identidad. 
En su obra Totalidad e Infinito, Lévinas expone la cuestión del rostro y la exterioridad, como el movimiento de salir de la subjetividad del sí mismo hacia la subjetividad de reconocimiento del otro. En el reconocimiento del otro se produce el acontecimiento ético.

Como ya se ha dicho el rostro revela la posibilidad de la dimensión ética, "la epifanía del rostro es ética" (Lévinas, $2006,213)$. Se presenta como la resistencia ética, es la presencia de lo infinito. Por su epifanía, por su apariencia que la exterioridad del ser infinito puede manifestarse como resistencia. La relación de la resistencia es según Lévinas, establecida con el otro en absoluto, que es una resistencia sobre aquello que no resiste, es decir, una resistencia ética.

La relación con el rostro, sin duda, puede ser dominado por la percepción, pero lo concreto es que el rostro no se reduce a ella, el rostro es lo que no se puede matar, o por lo menos el significado de lo que quiere decir: "no matarás". El intento de poner fin a la dominación del Otro por el Mismo es el asesinato que, en última instancia, es el fracaso de este intento, porque en el momento de la muerte el Mismo, en cuanto infinito, escapa quedando solamente el cadáver, el puro existir indeterminado. Esta prohibición de matar, revelado por el rostro, no es una exigencia ontológica, sino ética. Para Lévinas, el acceso al rostro es, inicialmente, ético. El rostro que expresa una pobreza esencial, que está expuesto, amenazado y al mismo tiempo que me invita a la acción violenta, es la significación que me prohíbe matar.

El rostro del otro, presencia de lo infinito, por lo tanto, revela la imposibilidad del asesinato,

"este infinito, más fuerte que el homicidio, ya nos resiste en su rostro, y su rostro es la expresión original, es la primera palabra: no matarás. Lo infinito paraliza el poder con su resistencia infinita al homicidio, que, duro e inseparable, brilla en el rostro del otro, en la desnudez de su total de sus ojos, sin defensa, en la desnudez de la apertura absoluta de lo Transcendente. Ahí hay una relación, no con una resistencia mayor, sino con algo absolutamente Otro: la resistencia del que no presenta resistencia: la resistencia ética" (Lévinas, 2006, 212).

Tal revelación del rostro, que es sobre todo la revelación de su infinitud, revelación de su diferencia, compromete y evoca, es decir, es ella que se revela y enseña significando.

De esta manera, el infinito, según Lévinas, no es apático, pasivo y parte de él el primer movimiento que ya se revela como resistencia de aquello que no ofrece resistencia alguna, esto es, resistencia ética que llega antes de toda y cualquier acción del Mismo y que por ser ética rompe con el movimiento violento de una consciencia de lucha. Dicho de otra manera, la epifanía o revelación del Rostro instaura la ética, pues si ni fuese así, perpetuaríamos una redundancia del Yo. La resistencia ofrecida por el Rostro se configura como anterior a la propia consciencia, va más allá de esa consciencia y, por ese motivo, la condiciona de forma positiva, es decir, la resistencia instaura proximidad:

lo infinito se presenta como rostro en la resistencia ética que paraliza mis poderes y se erige dura y absoluta desde el fondo de los ojos, sin defensa con desnudez y miseria. La comprensión de esta miseria y de esta hambre instaura la proximidad misma del Otro. Pero así es como la epifanía de lo infinito es expresión y discurso (Lévinas, 2006, 213).

Es importante observar el modo por el cual Lévinas hace una inversión del propio sentido de la subjetividad, representando su dependencia en relación al 
Otro. Así, la subjetividad no es más comprendida en cuanto algo que se yergue de las fuerzas de su propio interés, ni del ejercicio de sus propias habilidades o de su libertad, pero es respuesta al llamado del otro, es según en relación al Otro, se puede hasta decir que ella depende del Otro por la revelación de su infinitud.

A partir de esto, según Lévinas, al afirmar el Yo se asume un lugar privilegiado en relación a las responsabilidades, una posición insustituible en medio a un llamado imposible de ser desconsiderado, como se ahí se estuviese dispuesto a las exigencias igualmente infinitas,

el ser que se expresa se impone, pero precisamente al llamarme desde su miseria y desde su desnudez -desde su hambre-, sin que pueda hacer oídos sordos a su llamada. De suerte que, en la expresión, el ser que se impone no limita sino que promueve mi libertad, al suscitar mi bondad. El orden de la responsabilidad en el que la gravedad del ser ineluctable congela todo reír, es también el orden en el que la libertad es ineluctablemente invocada, de suerte que el peso irremisible del ser hace surgir mi libertad (Lévinas, 2006, 213-214).

Es como si existir ahora sólo tuviera sentido como existir para el Otro. Es como si la desnudez del otro exigiera todas las fuerzas de la subjetividad, como si delante del pobre, del extranjero, de la viuda y del huérfano, de aquel que nada tiene, pero en el cual brilla la altura del infinito, surgiera una sensación de indignidad que desemboca necesariamente en responsabilidad, lo que crea un nuevo contexto extremadamente pesado a la subjetividad.

Tiegüe Vieira (2007) sobre la obra Totalidad e Infinito de Lévinas, muestra de una manera precisa la categoría de Alteridad, que es producida en la revelación del rostro del otro, y que, al mismo tiempo, hace que suceda la abertura para la exterioridad, para el infinito, esto conlleva a la responsabilidad por el otro:

Lévinas entiende que el yo no se debe al ser, mas al Otro. Es a partir del otro, del Yo poniéndose a la escucha por su llamado, en la capacidad del Yo voltearse completamente para y por el Otro, que surge propiamente el Yo en cuanto consciencia. $Y$ esta relación es ya la consecuencia de la responsabilidad como fundamento ético primero. Se puede entender, en un primer momento, la categoría de alteridad como una relación responsable y ética, pues contiene y revela la posibilidad de aquel que está más allá del ser y de la identidad del mismo como un transcender para el otro dentro de un relación responsable. (p.11).

A lo que agrega Tiegüe Vieira (2007):

La cuestión ética para Lévinas, no es, por tanto, apenas más un problema de entre tantos tratados por la filosofía, mas el que constituye la propia estructura de determinación de la vida humana, se es considerada profundamente. Así, el problema central de la filosofía, según Lévinas, y que se amplia para la vida común, es de fondo ético. Su filosofía es, por lo tanto, una tentativa de lanzar un nueva forma de mirar las relaciones entre el Yo y el Otro, una relación que Lévinas intenta mostrar ser ética. (p. 11-12). La categoría de alteridad, pensada levinasianamente, abre camino para una nueva posibilidad que se da como abertura a la exterioridad, al reconocimiento del otro en su forma radical, en su vestigio del infinito, así, escapando a la totalización y a la dominación (Vieira, 2007,13).

El rostro, por lo tanto, donde se presenta lo absolutamente Otro es todavía la alteridad absoluta, que no niega el Mismo violentándolo, por el contrario, caracterizase por la no violencia por excelencia, llamando a la responsabilidad y 
a implantarlo. Al respecto Jazmín Riatiga (2008) afirma que:

Lévinas desarrolló la idea de que la presencia del "Otro" (y, más concretamente, del rostro del Otro), que representa la conciencia moral que tiende a rechazar toda violencia con respecto al Otro; es una experiencia fundamental que genera pautas de reconocimiento del otro en la presencia del conflicto. Se trata de una experiencia concreta que compromete al individuo en tanto que sujeto moral, sin que haya con el Otro ningún contrato: el deber del hombre hacia el Otro es incondicional, y eso es lo que funda la humanidad del hombre. Para Lévinas, el hombre es "más que ser". La relación ética que impone el rostro del Otro conduce a que sea posible leer su huella (Riatiga, 2008, 55).

Sintetizando Jonathan A. Castelblanco (2009) en su estudio sobre la alteridad levinasiana afirma que:

Con el planteamiento de la alteridad Lévinas substituye definitivamente la ontología por la ética, como la única alternativa en favor de un humanismo que reivindica el lugar del Otro en la sociedad y en el mundo. La filosofía de nuestro autor responde entonces a este camino filosófico llamado a escuchar el rostro humano del Otro a partir del imperativo ético: "no matarás". Ante esta demanda, la responsabilidad es aquella respuesta para-el-otro que me exige dicho rostro y posibilita relaciones éticas en función de una sociedad más humana. (p.14) Desde esta perspectiva, Lévinas, movido por el afán de replantear las condiciones de un humanismo del Otro hombre, propone que mediante la relación con el Otro, el hombre sea capaz de darle un sentido a su vida y a su ser. He aquí la apuesta levinasiana por mantener aquello que en fin, es la sublimidad del verdadero "hacerme cargo" por el Otro. Desde esta perspectiva, nuestro autor insiste en la obligación incoercible de filosofar, mediante la lucha por lo humano en el hombre. Esta lucha obedece al nombre de la responsabilidad que es, a su vez, la respuesta del sujeto al llamado imperativo del rostro, al que no puedo huir, porque me obliga a responder por el Otro, pues yo soy el primero y el último responsable por él. (p.115).

\subsubsection{El horizonte de la educación como formación ética}

Estudiado la categoría de la alteridad de Lévinas, se procede ahora a hacer el análisis de la importancia de la formación ética en la educación y posteriormente visualizar cómo esa ética levinasiana se convierte en elemento importante en el conocimiento de la formación ética.

Muchas veces se ha afirmado que la educación se asienta -al menos desde el horizonte normativo que dibuja una aspiración ética ideal- en una genuina preocupación por acoger y proteger lo más humano que hay en el hombre. La vocación educativa -la voz interior que puede reclamar a todo educador- es, así, custodiar la presencia de la humanidad en cada uno (Bárcena y Melich, 2000, 125). Es decir, el educador debería tener como vocación ayudar en la formación integral del ser humano. De forma breve, el concepto de "formación" significa "ascenso a la humanidad"; desarrollo del hombre, en tanto hombre (Orozco Silva, 2002, 25).

Ese horizonte de la eticidad en la educación, es presentada también por Edgar Morin (1999), como uno de los siete saberes necesarios para la educación del futuro:

La educación debe conducir a una "antropo-ética», considerando el carácter ternario de la condición humana, que es el de individuo, sociedad, especie. En este sentido, la ética individuo/especie necesita un control mutuo de la sociedad por el individuo y del individuo por la sociedad, 
es decir la democracia; la ética individuo, especie convoca a la ciudadanía terrestre en el siglo XXI. La ética no se podría enseñar con lecciones de moral. Ella debe formarse en las mentes a partir de la conciencia de que el humano es al mismo tiempo individuo, parte de una sociedad, parte de una especie. Llevamos en cada uno de nosotros esta triple realidad. De igual manera, todo desarrollo verdaderamente humano debe comprender el desarrollo conjunto de las autonomías individuales, de las participaciones comunitarias y la conciencia de pertenecer a la especie humana (p.11).

Se trata de desarrollar, con la mediación de la educación, una antropo-ética que supone la decisión consciente y clara de asumir la condición humana individuosociedad-especie en la complejidad de nuestro ser; de lograr la humanidad en nuestra conciencia personal y asumir el destino humano en sus antinomias y su plenitud (Orozco , 2002, 37).

Por lo tanto, el paradigma tecnológico en la educación es insuficiente. Pedro Ortega Ruiz en su artículo "La educación Moral como pedagogía de la alteridad", hace un buen análisis de la problemática en relación la formación ética en la educación:

Durante décadas, se ha pensado y realizado la educación desde el patrón de la eficacia. El control de las variables que operan sobre los procesos de enseñanzaaprendizaje se ha convertido en la preocupación prioritaria de la investigación y praxis pedagógicas. "Dar cuenta", explicar lo que sucede en el aula ha sido y es la gran aspiración del saber pedagógico. Con ello se ha aumentado, sin duda, el nivel de racionalidad y optimización de la acción educativa, superando una etapa de prácticas vinculadas exclusivamente al sentido común o a la experiencia acumulada. Pero esta preocupación por la eficacia y el control de los aprendizajes, sin duda necesaria en la acción educativa, no ha dado lugar, en la misma medida, a una enseñanza mejor en todas las dimensiones de la persona. Una pedagogía más racional y científica no ha dado paso a una pedagogía con rostro humano. Aún siguen vigentes paradigmas que durante años han configurado la enseñanza intentando, en vano, someterla a niveles de control y racionalidad equiparables, en sus propósitos, a los procesos industriales. No estoy abogando, con estas afirmaciones, por volver a tiempos pasados, ni tampoco renunciar a introducir nuevos elementos que eleven el nivel de racionalidad en los procesos educativos. Sí digo que el uso predominante de la razón tecnológica en la enseñanza convierte a nuestros alumnos en máquinas especializadas de una gran eficacia, pero que si se quiere llegar a ser un individuo más humano, no se puede relegar a un segundo plano la apropiación de los valores morales que hacen del "homo sapiens" un ser humano. En las aulas existe toda una trama de relaciones que no pueden explicarse mediante metodologías de corte positivista: intersubjetividad, interacción, comunicación, ética...; en las aulas fluye una corriente de vida (el mundo de la vida, en expresión de Husserl) que se resiste a ser explicada desde metodologías positivistas (Ortega Ruiz, 2011).

\subsubsection{La importancia del conocimiento de la teoría ética de la alteridad de Lévinas en la formación ética en la educación}

La reflexión busca si la ética de la alteridad de Lévinas contribuye para que el discurso ético en las comunidades educativas no sea vacio y de relleno, $y$, al contrario dé sentido a la construcción del ser humano y de la convivencia. Entonces, ¿Qué aporta realmente la ética de Lévinas a la pedagogía? ¿Por qué se toma como punto de referencia fundamental para la formación ética en la educación? 
Jorge Schemes (2007) trata del tema de la ética de la alteridad en la educación, y para ello toma el pensamiento de Lévinas como base para pensar la cuestión. Comienza diciendo que: hay que indagarse cen qué tipo de teoría está fundamentado la práctica de la educación? Acaso ¿son teorías que revelan una práctica excluyente? Conclúyase que el sentido y el significado de la ética de la alteridad en la educación sólo puede ser "aprehendido" cuando se "aprehende" el significado ético del rostro del otro, del diferente, del "totalmente otro". El rostro es la expresión del humano que se impone al anti-humanismo pos-moderno, que se presenta para nosotros en forma de consumismo y de violencia. La ética de la alteridad condena la segregación, la exclusión, los preconceptos y los prejuicios, para contemplar la, la solidaridad, la diversidad y la justicia (Schemes, 2007, 1). Ahora, Schemes dice que esta ética no es apenas un discurso vacio, debe primero ser interiorizada y vivida, para que pueda crear lazos y no separar o romper.

Schemes considera el planteamiento de Lévinas de la ética como filosofía primera, y la propone como la teoría ética que fundamente la categoría de la alteridad en el contexto de la formación ética en la educación.

El pensamiento sobre el ser como esencia de sí y para sí condujo a Lévinas al cuestionamiento ético como el centro de su pensar filosófico. Aunque Lévinas haya iniciado su pensamiento filosófico en las corrientes de la fenomenología de Husserl y en el pensamiento de Heidegger, él fue allende y emancipó su pensamiento filosófico estableciendo el Otro como prioridad ética (alteridad), y la ética como su fundamento filosófico. Se puede decir que la filosofía de Husserl y Heidegger está fundamentada en la idea del ser para sí, egocéntrico e individualista. Mientras que para Lévinas, tomó distancia de ellos, y la prioridad es el Otro en una relación ética. La interioridad y la individualidad emergen de la concreta relación del yo con el mundo exterior, concreto, real, palpable, con el otro, con la exterioridad del rostro del otro (Schemes, 2007, 2-3).

En otras palabras, lo que hace Lévinas con su filosofía de la alteridad, es alejarse de la herencia moderna de la concepción del sujeto como un ser autónomo y subjetivista, y propone un sujeto volcado hacia el Otro, un ser heterónomo. La filosofía moderna presenta un cogito orgulloso, soberano, capaz de darse la ley a sí mismo. La filosofía de la educación ha convertido esta autonomía del sujeto en su fundamento principal. Lévinas rompe con el idealismo de la modernidad, y convierte la heteronomía, la responsabilidad, en momento constitutivo y fundacional de la subjetividad. Es necesario desubjetivizarse, deponerse como ego, desertar de uno mismo para ser fiel a uno mismo (Bárcena y Melich, 2000, 136). Éste es el sentido que tiene la cita del Talmud de Babilonia con la que Lévinas da inicio uno de los capítulos de Humanismo del otro hombre: "Si yo no respondo de mí, ¿quién responderá por mí? Pero si yo solamente respondo de mí, ¿puedo ser todavía yo?" (Lévinas, 1987, citado en Bárcena y Melich, 2000, 136)

Delante de lo expuesto se propone la adopción de la ética de la alteridad de Lévinas como elemento importante en el contexto y conocimiento de la formación ética en la educación, tal propuesta se basa en la posibilidad de que esta es la ética que explica mejor el problema de las relaciones humanas. Al respecto dice Schemes (2007) que:

Para Lévinas, el principio ético de respeto a la alteridad es diferente. El rostro del otro nos llama, nos desafíos y nos invita. La ética de la alteridad en el rostro del otro revela su infinitud. Esta ética rompe paradigmas tradicionales establecidos por otras éticas. Lo que identifica al otro es su rostro, y es a menudo en el 
rostro del otro que encuentro mi propia identidad. Cada rostro es diferente, pero me da un sentido de respeto, cara a cara, ojo a ojo (la alteridad), me veo en el otro, porque hay un aviso cuando nos enfrentamos delante del rostro del otro. Así que cuando el maestro aprenda a mirar a los rostros de sus estudiantes y no sólo en el aula de clase, permitiendo al mismo tiempo de ser mirado, el sentido de respeto por los demás y lo que es diferente, surgirá. Esta sensación surge cuando identificamos el rostro del otro y permitimos ser identificado" (p.4-5).

Por eso, el rostro del otro convierte a la acción educativa en una recepción, en la respuesta a una llamada que precede el sujeto, como pasividad radical. El rostro hace de la educación responsabilidad, responsividad. El rostro, en su rostro, se me aparece "de frente", "cara a cara". El rostro es "presencia" no de una imagen, sino de una palabra. La ética no comienza con una pregunta, sino como una respuesta a la demanda del otro hombre. Esto es lo que significa heteronomía: responsabilidad para con el otro. (Bárcena y Méllich, 2000, 138-139)

Un gran reto para la educación y los educadores es utilizar el discurso de la ética de la alteridad en que las acciones deben incluir, es decir, internalizar los principios de relación ética con los demás, dando prioridad a lo propuesto por Lévinas. Y todo comienza por ver el rostro del otro, viendo y escuchando al otro, mirándole a los ojos y ver de cerca su rostro (la alteridad). No es una mirada superficial, es una expresión de empatía, sentir lo que el otro siente, sentir lo que piensa y cómo ve la vida. En resumen, es una ética de la alteridad que establece relaciones de empatía y de inclusión (cfr. Schemes, 2007,5-6).

El gran desafío es formar una conciencia crítica "autoconsciente" $y$ "alterconsciente" y establecer la coherencia entre la epistemología de la ética de la alteridad y la práctica de la ética en la cotidianidad de las relaciones interpersonales, ya sea dentro de la comunidad de la escuela o en la vida misma (Schemes, 2007, 6).

La manera de reconocer al otro como totalmente otro, conduce a la acogida, a una educación como hospitalidad. Bárcena y Méllich en la defensa de la heteronomía ética defienden la tesis que la educación debe encontrar una base para el ejercicio de la responsabilidad en el pasado, en el recuerdo y en la memoria. Se trata de transmitir, a través de la memoria, una ética de la atención, una actitud y unos medios para que las jóvenes generaciones sean más atentas que sus mayores (Bárcena y Méllich, 2000, 142).

Desde el lenguaje de una autonomía heteronomizada queda al fin claro que un educador se hace responsable no por lo que provoca -intencional o no intencionalmente- en el otro, sino también de la biografía y del pasado del otro. Esto es lo que significa hacerse cargo del otro, cuidar del otro. Me hago cargo del otro cuando lo acojo en mí, cuando le presto atención, cuando doy relevancia suficiente al otro y a su historia, a su pasado (Bárcena y Méllich, 2000, 146).

Pedro Ortega Ruiz (2011), habla de la pedagogía de la alteridad, con su reflexión aplica la teoría ética de la alteridad de Lévinas en el campo de la educación. Comienza diciendo que educar es y supone algo más que la simple implementación de estrategias o conducción de procesos de aprendizaje. Entiendo que la relación más radical y originaria que se produce entre educador y educando, en una situación educativa, es la relación ética que se traduce en acogida, no la relación profesoral-técnica del experto en la enseñanza; que la relación ética de acogida es lo que define a la relación profesor-alumno como relación educativa (Ortega Ruiz). (...) es la aceptación de la persona del otro en su realidad concreta, en su tradición y cultura, no del individuo 
en abstracto; es el reconocimiento del otro como alguien, valorado en su dignidad irrenunciable de persona, y no sólo el aprendiz de conocimientos y competencias. $Y$ esta relación ética es la que hay que salvar, si se quiere educar y no hacer "otra cosa". Pocas veces los educadores y pedagogos nos damos verdadera cuenta de lo que es y supone situarse ante un educando como alguien que demanda ser reconocido como tal. Educar exige, en primer lugar, salir de sí mismo, "es hacerlo desde el otro lado, cruzando la frontera"; es ver el mundo desde la experiencia del otro. Ello nos obliga a negar cualquier forma de poder, porque el otro (el educando) nunca puede ser objeto de dominio, de posesión o de conquista intelectual, por consiguiente, exige una respuesta responsable, es decir, ética a la presencia del otro (Ortega Ruiz). (...) No se acoge a un ser abstracto (al estudiante) sin pasado ni presente, sino a alguien que vive aquí y ahora. Y sus "circunstancias", en su pasado y su presente, son inseparables del acto de la acogida. De otro modo, hacerse cargo del otro no dejaría de ser una expresión vacía, carente de sentido o un puro sarcasmo. Si esta relación ética de acoger al otro y hacerse cargo de él no acontece, se da sólo enseñanza, instrucción, pero nada más. Por ello, la acogida en educación impulsa al realismo y nos mete de lleno en las condiciones socio-históricas en las que vive el educando. La realidad del sujeto no se reduce a sus características o rasgos personales; también su equipaje socio-cultural, sus condiciones de vida forman parte de "lo que es" cada individuo y no pueden permanecer al margen de los procesos educativos.

\section{Diseño metodólogico}

Por las características del estudio se adopto el enfoque de investigación cualitativa, que permite aprehender los sentidos y significaciones de la ética de la alteridad de Lévinas y su importancia en la formación ética en la educación.
El enfoque cualitativo, que bien podría llamarse de "procesos cualitativos", que se preguntan ¿cómo se interpretan los motivos de la acción humana? y ¿cómo se comprende lo interno y subjetivo del hombre?, han dado respuesta a las cuestiones fundamentales referidas al origen y sentido de la comprensión humana, las cuales han tenido un desarrollo intelectual importante desde el siglo XIX, a raíz de la complejidad que caracteriza a la sociedad postindustrial (Nava O. José).

De esta manera, sin duda el enfoque cualitativo es el más indicado dado que en este trabajo se hace un estudio de análisis e interpretación entre un tema filosófico como lo es la categoría de la alteridad de Lévinas y la relación con el quehacer pedagógico como lo es la formación ética en la educación. Esto pues, tanto la filosofía y las ciencias de la educación hacen parte de las ciencias del espíritu o de la interpretación.

El método de investigación se trabajó en un primer momento desde la estrategia bibliográfica, en la cual se debió tener en cuenta cinco pasos: delimitar el universo de la investigación, ubicar las fuentes bibliográficas, evaluar las fuentes bibliográficas, fijar el sentido literal de la obra, Interpretar los valores de la obra investigada (Álvarez H. y Niño M., 1992, 35). Esto se hizo con el fin de poder seleccionar entre una cantidad de textos, los más significativos para la investigación propuesta. Pues alrededor del estudio de la categoría de la alteridad de Lévinas hay una amplia gama de opciones investigativas. Los textos que se han seleccionado aparecen en la fundamentación teórica de este trabajo.

En un segundo momento se trabajó la estrategia de la investigación documental. Cuando se habla de investigación documental se hace referencia a "la actividad humana realizada para descubrir un conocimiento o solucionar un problema, al utilizar los documentos escritos o repre- 
sentativos como medio para lograr tal fin" (Rodríguez, 2005, 15).

Esta estrategia de la investigación documental se hizo para:

- Encontrar información relevante acerca del significado de la categoría de alteridad de la ética de Lévinas, primordialmente seleccionando las ideas principales de obras del propio autor y de obras y artículos de expertos que ya han estudiado el pensamiento de él

- A partir de la reunión, interpretación, evaluación y reporte de datos teóricos comprender porque es importante la teoría ética de Lévinas entre las diversas teorías éticas actuales.

- Además, se presentó la conexión de ideas entre varios autores y las ideas del investigador, para analizar qué importancia tiene el conocimiento de la teoría ética de la alteridad de Lévinas en la formación ética en la educación, y de esta manera reflexionar si la ética de la alteridad de Lévinas contribuye para que el discurso ético en las comunidades educativas no sea vacio y de relleno, $y$, al contrario dé sentido a la construcción del ser humano y de la convivencia.

La información se recopiló mediante diferentes técnicas y recursos propios de la investigación cualitativa de carácter teórico: revisión bibliográfica, técnicas de investigación documental. Por el carácter teórico de la investigación, son los textos escritos y textos virtuales los instrumentos que se utilizan para extraer la información que se requiere para el posterior análisis.

La interpretación se realizó mediante el cruce de la interpretación del investigador, los datos teóricos de la categoría de la alteridad de Lévinas, y la información sobre la importancia del pensamiento de
Lévinas en la formación ética en la educación, al mismo tiempo que se hizo un análisis para visualizar la importancia del discurso ético de Lévinas en la búsqueda de sentido de la construcción del ser humano y la convivencia.

De esta manera se sistematizaron y se analizaron los datos teóricos acerca de la información, arrojando los resultados proyectados.

\section{Resultados}

Los resultados que se presentan a continuación se hacen en base a la fundamentación teórica, la interpretación del autor y la experiencia en la docencia. Los resultados buscan responder a los objetivos planteados, y de esta manera verificar o falsear los propósitos fijados en esta investigación.

\subsection{El significado e importancia de la categoría ética de la alteridad de Lévinas en la actualidad}

\section{Primera constatación}

Al empezar esta investigación era necesario conocer el significado de la categoría de la alteridad como fundamento de la ética, y así poder hacer un análisis en relación a la formación ética en la educación. A partir del estudio realizado se constata que el concepto de la alteridad es sin duda la categoría principal del cuerpo filosófico del autor, pues en ella está patentada la tesis central levinasiana de considerar la ética como filosofía primera. De esto se trata el gran giro epistemológico que realizó Lévinas al considerar la ética y no la ontología como la filosofía primera.

¿Qué significa para Lévinas que la ética sea "la filosofía primera"? Francisco Amoraga (2005) sobre la filosofía de Lévinas afirma lo siguiente: 
Que el orden de las primeras preguntas ha quedado invertido para la filosofía. A la pregunta por el ser antecede la pregunta por la escandalosa muerte del otro hombre. Es más, para Lévinas, la filosofía ni siquiera tiene un origen interrogativo sino imperativo: su programa se reduce al mandato ético "No matarás". La responsabilidad por el otro hombre apunta a la de-posición del sujeto, un sentido de la subjetividad que precede a la identidad del sujeto consigo mismo. A partir de este carácter antecedente de la relación con el otro, la ética se constituye en filosofía primera. Del camino hacia esta tesis, Lévinas invalida la primacía de la ontología y rehabilita la metafísica como el cuestionamiento del yo por el otro, o sea, la rehabilita como ética. (Amoraga, 2005).

De ahí que la principal preocupación en su pensamiento se refiere a la relación interhumana, en el sentido de repensarla y proveerla de un nuevo prisma comprensivo. Esto se comprende teniendo en cuenta el contexto socio histórico que el autor tuvo que vivir. Lévinas vivió una experiencia muy traumática con la segunda guerra mundial, fue mantenido preso por el régimen nazista, más allá de tener sus padres y hermanos ejecutados. Pudo vivir de cerca las atrocidades cometidas por la dicha "razón iluminada", que se mostró violenta y totalitaria en su extremo. ${ }^{4}$ Estas experiencias, en gran medida, son tensiones que forman su pensamiento.

4 Al respecto de estas experiencias de atrocidades Lévinas expresa lo siguiente: "es la experiencia fundamental de mi vida y de mi pensamiento, el presentimiento de esos años terribles, el recuerdo imborrable de esos años. Pero no pienso que la salida pueda consistir en un cambio de los principios de esta civilización. Pienso que en su interior hay quizá, si ponemos en el centro elementos que fueron considerados laterales, una salida. No he olvidado que esta Europa se encuentra, sin decirlo, sin confesarlo, en la angustia de la guerra nuclear. Me parece que lo que a menudo se llama Modernidad se coloca entre los recuerdos imborrables y una espera angustiosa. No sé si, renunciando a ello, aceptando formas que son ciertamente humanas, que puede humanizarse todavía más, se encontrará una respuesta a nuestras angustias. No espero mucho de mis investigaciones para cambiar eso, pero en todo caso están determinadas por lo que considero un desequilibrio, propio de esta civilización, entre los temas fundamentales del saber y los de la relación con el otro." LÉVINAS, Emmanuel. La asimetría del rostro, entrevista a Emmanuel Lévinas (MARTOS, Andrés Alonso, 2008. p.20-21).
Lévinas quiere, por lo tanto, romper con esta racionalidad construida a lo largo de la historia del pensamiento occidental así como a lo largo de la historia de la filosofía, en que la relación Yo-Otro siempre fue tratada como una relación sujeto-objeto, subordinada a una relación de conocimiento (Vieira, 2007, 9-10).

Su crítica, por lo tanto, se revela como crítica al primado ontológico que se afirma tanto como fundamento de la verdad en cuanto filosofía primera. Según Lévinas, la ontología tendría su papel dentro de la metafísica, pero no sería el de la filosofía primera. Lévinas rescata el concepto de metafísica atribuyéndole un nuevo significado: mantiene el sentido de transcendencia al mismo tiempo que invierte su sentido para una relación interhumana. Lévinas propone, por lo tanto, no el fin, pero si otro entendimiento de la metafísica al idealizarla no en cuanto tarea de permitir el acceso al ser, pero si en cuanto momento en que se puede transcenderlo en el deseo del infinito, en la relación con el Rostro. La metafísica, según Lévinas, seria esa tendencia constante de ir más allá del ser. (Vieira, 2007, 10-11). Se invierte de este modo, la salida de la ontología para la relación ética, invirtiéndose también la posición del sujeto, que ahora no es más el Yo egoísta que direcciona el orden del entendimiento y del sentido, al contrario se fundamenta en el otro que se revela y se ofrece al yo como totalidad de significación, suplicando para no ser tematizado ni transformado en concepto. (Vieira, 2007, 11).

La ética para Lévinas está más allá del Ser. Se podría decir que después de Auschwitz su preocupación no podía quedar remitida a los "modos de ser", "a la comprensión del ser" sino la pregunta es referida a la ética, es decir a la relación del ser con el Otro, con la responsabilidad con el Otro, en el encuentro con el Otro. La ética para Lévinas no es lo que se refiere comúnmente como moralidad 
o un código de comportamiento. Para Lévinas, ética es una llamada a cuestionar el "igual" desde el Otro. A ser responsable del Otro (Magendzo, 2004, 1-2). Al respecto manifiesta Lévinas:

Soy responsable del otro, respondo por el otro. El tema principal, mi definición fundamental, es que el otro hombre, que en principio forma parte de un conjunto que abarca todo y que me es dado como los otros objetos, como el conjunto del mundo, como el espectáculo del mundo, rompe de algún modo ese todo precisamente por su aparición como rostro. El rostro no es simplemente una forma plástica, sino de entrada un compromiso para mí, una llamada, la orden de ponerme a su servicio. No sólo del rostro, sino de la otra persona que en ese rostro me aparece a la vez en su desnudez, sin medios, sin nada que la proteja, en su indigencia, y al mismo tiempo como el lugar en que recibo un mandato (Lévinas, en Martos, 2008, 21).

La cuestión ética para Lévinas, no es, por consiguiente, apenas más un problema de entre tantos tratados por la filosofía, mas el que constituye la propia estructura de determinación de la vida humana, si es considerada profundamente. Así, el problema central de la filosofía, según Lévinas, y que se amplia para la vida común, es de fondo ético. Su filosofía es, por lo tanto, una tentativa de lanzar una nueva forma de mirar las relaciones entre el Yo y el Otro, una relación que Lévinas intenta mostrar ser ética. (Vieira, 2007, 11-12).

\section{Segunda constatación}

También se propuso en este trabajo comprender por qué es importante la teoría ética de Lévinas entre las diversas teorías éticas actuales, cuál es su importancia. Y lo que se verifica es que la teoría ética levinasiana es uno de los máximos referentes teóricos de análisis de la acción del ser humano en la actualidad, del "qué se debe hacer", esto, porque Lévinas revisa el sentido de la interrelación del ser humano.

Al poner en escena la cuestión de lo ético, tal como Lévinas lo entiende, se piensa en corresponder a un llamado inherente al propio contexto sociocultural contemporáneo, en el cual una crisis de la subjetividad de vasto alcance y graves consecuencias impone que se asuma con decisión la siempre renovada cuestión sobre el sentido humano (Costa, 2007, 12).

Dos guerras mundiales, guerras localizadas, genocidios totalitarios, la globalización del sistema de Mercado y el acelerado progreso de las biotecnologías, el uso de la tecnología en beneficio de guerras y violencia, hicieron con que, desde el siglo pasado, la reposición de la cuestión sobre el sentido de lo humano hubiera asumido una sincera actualidad, con rasgos de urgencia. En efecto, por ejemplo, Len qué sentido se puede todavía hablar de sujetos autónomos, en un sistema social en que las decisiones individuales son regidas, en última instancia, por el Mercado? ¿Cómo hablar todavía de sujetos diferentes, en un sistema social en que los individuos son ecualizados a partir y en función del valor de cambio? ¿Cómo siquiera hablar, todavía, de sujetos humanos, cuando el dominio de las ingenierías genética y cibernética está a un paso de facultar, con las figuras del "clon" y del "robot", la casi reproducción técnica de individuos de la especie? Delante de los desatinos a que llegó la civilización occidental moderna, erguida en nombre de valores supuestamente universales, vuelve a la escena el desafío de movilizar una profunda y rigurosa revisión de los fundamentos éticos, a fin de escrutar que dimensiones de lo humano- y que 
valores correspondientes- pueden resistir las crisis y las criticas, a punto de abrir el advenimiento de un nuevo y consistente sentido de la civilización (Costa, 2007,12).

Frente a esto, Lévinas asume la cuestión del sentido de lo humano en el centro de su pensamiento, llegando a promover un significativo cambio epistemológico en la historia del pensamiento occidental moderno, al sustentar la proposición de la ética como filosofía primera. Esta proposición significa en primer lugar, el reconocimiento de la anterioridad y de la primacía de la cuestión ética. Es la asunción de la posición ética como perspectiva fundadora del sentido, que posibilita una comprensión suficiente de los diversos campos de sentido y de acción humanos. Es decir, solamente a partir de la ética, y en ella, la racionalidad encuentra su verdadero estatuto; fuera de la ética, encerrada exclusivamente en sí misma, la razón peligra en sucumbir en el riesgo de permanecer integralmente coherente consigo misma -lógica- $y$, al mismo tiempo, deshumana. Hecho que es testimoniado por los estados totalitarios, eminentemente organizados en su mecánica y, en la misma proporción, violentos en su acción (Costa, 2007, 13). En suma, en Lévinas la ética es la óntica. Por otro lado, Lévinas tampoco se alinea a las corrientes dichas "posmodernas" que, poniendo en jaque los principios modernos de la consciencia y la libertad, reducen el sujeto a una serie de saberes y de lenguajes socialmente constituidos, concluyendo por su falencia (Costa, 2007, 14).

Delante de la urgencia de la cuestión del sentido humano y de la insuficiencia de las perspectivas moderna clásica y posmoderna, asistimos, en Lévinas a la emergencia de otra posibilidad de sentido. Entre la subjetividad absoluta moderna y la "muerte del sujeto" posmoderna, el pensamiento levinasiano mira otra subjetividad, que no se nuclea en torno de propiedades ontológicas o de la actividad autoreflexiva de la consciencia, pero si en la vocación a responder por el otro, a hablar por su alteridad o substituirla, vocación en la cual radica lo que Lévinas denomina ética. Subjetividad, por lo tanto, como responsabilidad o uno-para-el-otro. (Costa, 2007, 14-15). Claro está, que esto no se resume a la iniciativa del sujeto en dirección al Otro -por ejemplo, en la aplicación de normas que busquen protegerlo-, pues, en esa iniciativa, el sujeto, a rigor, no llega a salir de sí mismo y permanece como centro constituido de la realidad, acabando por asimilar la alteridad del Otro a su propia identidad. El Unopara-el-Otro -y en esto reside el núcleo del proyecto levinasiano- sólo puede cumplirse como pasividad o afección, esto es, como aptitud a ser afectado por el otro y a recibirlo en sí mismo. Tal aptitud a ser afectado -o vulnerabilidadconstituye, según Lévinas, el propio de la sensibilidad ética, cuyo analogón por excelencia es la maternidad (Costa, 2007, 15).

Interiorizar la relación de dependencia o responsabilidad ética para con los otros, aun con los desconocidos, significa que vivir no es un asunto "privado", sino que tiene repercusiones inevitables mientras sigamos viviendo en sociedad. Significa, en una palabra, que nadie me puede ser indiferente. Frente a cualquier otro he adquirido una responsabilidad, una dependencia ética de la que no me puedo desprender aún antes de que él me pueda pedir cuentas (Ortega Ruiz). Aún más:

El lazo con el otro no se anuda más que como responsabilidad, y lo de menos es que ésta sea aceptada o rechazada, que se sepa o no cómo asumirla, que se pueda o no hacer algo concreto por 
el otro... yo soy responsable del otro sin esperar la recíproca, aunque ello me cueste la vida. La recíproca es asunto suyo. Precisamente, en la medida en que entre el otro y yo la relación no es recíproca, yo soy sujeción al otro; y soy "sujeto" esencialmente en este sentido (Lévinas, 1991,91-92, citado en Ortega Ruiz).

$Y$ esta responsabilidad para con el otro, "que viene sin previo aviso", es lo que me constituye en sujeto moral.

\subsection{La importancia de la teoría ética de la alteridad de Lévinas en la formación ética en la educación}

Una vez comprendida la categoría de la alteridad de Lévinas y de su importancia en la actualidad dentro de la reflexión ética, se procedió a responder ¿qué importancia tiene en la formación ética en la educación? En la reflexión de esta cuestión subyacen varios cuestionamientos: ¿Qué discurso o que ética está siendo teorizada en las comunidades educativas? ¿Qué sentido tiene realmente formar en valores a partir de la ética? ¿Qué significa traer el discurso ético de Lévinas para un contexto educativo?

La constatación que se hizo es que una educación basada en la transmisión de conocimientos tecnológicos y científicos de corte positivista y conductista no es suficiente para formar al estudiante como un ser humano integral. Es el elemento ético puesto en cuestión lo que ayuda a comprender el hecho educativo como formación integral. Pues en el núcleo mismo de la acción educativa no está, por tanto, en la relación profesoral-técnica de experto en la enseñanza, sino la relación ética que la define y constituye como tal acción educativa. Esto obliga a una revisión completa de los contenidos de las estrategias actuales en educación moral. Y obliga, además, a enfocar la educación moral desde otro paradigma que tenga como protagonista no el sujeto autónomo de la moral kohlbergiana y de la ética discursiva, de raíces kantianas, sino la primacía del otro que nos constituye en sujetos morales cuando respondemos de él. Cualquier discurso pedagógico es deudor de una antropología y de una ética, está situado y responde a un contexto, es alimentado por las experiencias a la luz de una tradición (Ortega Ruiz), y la ética levinasiana bien fundamenta estos principios con su abordaje teórico.

Entonces, se reconoce que en la formación ética en la educación, la teoría ética levinasiana es un elemento importante como referente teórico, que encuentra en el reconocimiento del otro su punto de partida, lo que lleva a situar, por coherencia, un nuevo modelo de educación moral, la de la alteridad. De ahí que la relación que se establece entre docente y estudiante, en el proceso de enseñanzaaprendizaje, debe ser una relación ética que se traduce en una actitud de acogida y un compromiso con el educando, es decir, hacerse cargo de él ( Ortega Ruiz).

Es posible, entonces, hablar de una pedagogía de la alteridad tal cual como lo propone Pedro Ortega Ruiz. Desde la pedagogía de la alteridad, el proceso educativo se inicia con la mutua aceptación y reconocimiento de maestro y alumno, en la voluntad de responder del otro por parte del profesor, en la acogida gratuita y desinteresada que presta al alumno de modo que éste perciba que es alguien para el profesor y que es reconocido en su singularidad personal. Sin reconocimiento del otro y compromiso con él no hay educación. Por ello, cuando hablamos de educación estamos evocando un acontecimiento, una experiencia singular e irrepetible en la que la ética se nos muestra como un genuino acontecimiento, en el que de forma predominante se nos da la oportunidad de asistir al encuentro con el otro, al nacimiento (alumbramiento) de algo nuevo que no soy yo. En esta 
aventura, lo que quizás aprendemos es a disponernos, a ser receptivos, a estar preparados para responder pedagógicamente a las demandas de una situación educativa en la que otro ser humano nos reclama y nos llama (Ortega Ruiz). En la pedagogía de la alteridad la acogida del otro significa sentirse reconocido, valorado, aceptado y querido por lo que uno es y en todo lo que es. Significa confianza, acompañamiento, guía y dirección, pero también aceptar ser enseñado por "el otro" (educando) que irrumpe en nuestra vida (educador).

Por consiguiente, vista la importancia de la categoría de la alteridad en la formación ética en la educación, queda como recomendación y a la vez, desafío, cómo llevar a la práctica curricular el espíritu de la pedagogía ética del reconocimiento del otro, del uno-parael-otro, y de esta manera construir un discurso ético lleno de sentido y que ayude en la construcción y significación de vida de los estudiantes y docentes, y no quedarse meramente en una educación de transmisión de conocimientos tecnológicos y científicos de corte positivista y conductista, preocupada por formar profesionales sin esencia de vida.

\subsection{La teoría ética de la alteridad de Lévinas como discurso que da sentido a la construcción del ser humano y la convivencia}

Comprendida la categoría de la alteridad de Lévinas y de la importancia que tiene en la formación ética en la educación se pudo reflexionar si la ética de la alteridad de Lévinas contribuye para que el discurso ético en las comunidades educativas no sea vacío $y$ de relleno, $y$, al contrario dé sentido a la construcción del ser humano y de la convivencia. A partir del análisis de la fundamentación teórica y de la experiencia en la docencia se proponen dos contribuciones de sentido que hace la teoría ética levinasiana: la Formación integral del estudiante y la formación en ciudadanía y derechos humanos.

\section{La Formación integral del estudiante}

Un sistema educativo que se base en la pedagogía de la alteridad, cuya acción es traducida en la acogida, en el "hacerse cargo del otro", conlleva a una práctica pedagógica que contribuya a la formación integral del estudiante. La pedagogía de la alteridad en el reconocimiento del otro en cuanto otro, promueve que al estudiante se le eduque no como un mero ser profesional, a partir de la formación en tecnología y ciencia, sino en su totalidad en cuanto persona. Hay un reconocimiento del estudiante como una persona que se presenta ante mí para acogerlo y ser responsable por él, y ayudarlo a formarlo integralmente en todas sus dimensiones y no meramente una parte de él, con una actitud dialógica y de inclusión.

Acoger es hacerse presente, desde experiencias valiosas, en la vida de los educandos como alguien en quien se puede confiar. En la acogida, el estudiante empieza a tener la experiencia de la comprensión, del afecto y del respeto hacia la totalidad de lo que es, experiencia que puede ver plasmada también en los demás compañeros de aula porque ellos también son acogidos. En adelante, el aprendizaje de la tolerancia y el respeto a la persona del otro lo asociarán con la experiencia de ser ellos mismos acogidos, y no sólo en lo que la tolerancia tiene de respeto a las ideas de los demás, sino de aceptación de la persona concreta que vive aquí y ahora y exige ser reconocida como tal. La acogida, en educación, es reconocimiento de la radical alteridad 
del estudiante, de su dignidad inviolable (Ortega Ruiz).

La educación como experiencia de acogida, no sólo en el docente sino también en el estudiante (reconocimiento del otro y hacerse cargo de él), facilita la creación de un clima moral en las instituciones educativas y en las aulas de clase como "condición ambiental" para el aprendizaje de los valores socio-morales. Obviamente, no se entiende la acogida como un recurso útil para "moralizar" la vida de las instituciones educativas con un listado de prescripciones que regulen el comportamiento de estudiantes y docentes. Se habla de "otra moral", la que nos hace responsables de los otros y de los asuntos que nos conciernen como miembros de una comunidad educativa, empezando por la propia institución educativa.

Entender la educación desde la ética de la alteridad, como acto y actitud ética de acogida, libera de un intelectualismo petrificante, y obliga a hacer recaer la acción educativa no tanto en las ideas, creencias y conocimientos cuanto en la persona concreta del educando, a partir del contexto vital. Entender la educación desde la radical alteridad del estudiante es proyectar la educación como una acción responsable de afirmación y reconocimiento del otro en todo lo que es, como acogida y recepción de la persona, no de una parte de ella. Es la persona del estudiante quien se constituye en objeto de mi acogida, de mi dependencia ética, no sus ideas y creencias. Estas tan sólo le acompañan.

\section{La formación en ciudadanía y derechos humanos}

Un contexto educativo que se base en la radicalidad de la alteridad levinasiana, la acción de la práctica pedagógica es también traducida en la formación de docentes y estudiantes en una cultura del reconocimiento del otro, en la apre- hensión del sentido ético del rostro del otro, de la búsqueda de la justicia, de la buena ciudadanía y de la afirmación de los derechos humanos. Al respecto Pérez (2007), afirma que:

Lévinas nos da pistas decisivas para la cuestión ética que se plantea al término de la problemática de los derechos humanos. En la perspectiva moral de la reflexión ética que plantea Lévinas es donde nos podemos "hacer cargo" del problema del sentido que acucia a nuestra humanidad. Mas lo que él nos dice bien se puede anticipar resumidamente en la consideración de que el descubrimiento de sentido de nuestra subjetividad en la apertura al otro que nos interpela, que nos cuestiona y que nos convoca a la justicia. (Pérez, 2007, 232).

Ese sentido de responsabilidad conlleva a un compromiso político, que tiene una dimensión social, porque contempla inevitablemente la relación a un "tercero". En este sentido Pérez (2007) dice que:

El tercero, el "otro del otro", nos obliga a cada uno a salir fuera del ámbito doméstico, de la privacidad, "desinteresándonos" respecto de lo nuestro. La relación social se amplía, los círculos se rompen, las polaridades biunívocas se ven cuestionadas en el nosotros abierto en que nos descubrimos todos siendo cada uno no ya sólo el otro para un tú, sino el otro de muchos otros, para cada uno de los cuales también debemos ser, mediatamente, es decir, políticamente, "uno para el otro". Se abre así el espacio político para la justicia, si bien su raíz moral siempre ha de permanecer vivificándolo desde esa justicia primera que emerge en las relaciones interindividuales, en las cuales, sin embargo, queda subsumida en un amor que nunca ha de quedar atrás -contrapeso a la dureza de la ley, para que la pretensión de jus- 
ticia nunca se convierta en justiciera. (Pérez, 237-238).

La ética de la alteridad, de Lévinas no se queda en la relación "intimista" "yotú" en la que sólo intervienen individuos singulares, presentes en el mismo tiempo y espacio. El sujeto moral no puede responder únicamente del rostro singular cuya debilidad o extranjería le solicita, en este preciso momento, y abandonar a su suerte a los demás rostros, (...) la presencia del tercero introduce los derechos de todos los otros y no sólo de un rostro único. La educación, desde la alteridad, tiene una necesaria dimensión social. Es ética y política, es compasión y compromiso. Y despojar a la educación de estas dimensiones es reducirla al más puro adoctrinamiento. En tanto que es ética, la educación no está desligada de los problemas que afectan a los hombres concretos, sino que brota de ellos, de su derecho a una vida digna y justa, de su derecho a decir su palabra. (...) Y en tanto que educación, es en sí misma un acto social y político. Lo político forma parte de la naturaleza misma de la educación, por lo que los problemas de ésta no son exclusivamente pedagógicos, sino esencial y profundamente políticos. Educar es necesariamente un compromiso ético con el mundo. La finalidad de educar no se limita, por tanto, al ámbito de las características personales, "psicologizando" la educación, implica la formación del sujeto como ser social, incorporando toda la realidad de éste. $Y$ entonces, la educación no puede sustraerse a la función de transformación de la realidad social en la que el educando vive, de modo que le permita la realización de un ideal (valioso) de persona que toda educación lleva implícito (cfr. Ortega Ruiz).

Siguiendo esta misma reflexión, Abraham Magendzo (2004) sostiene que la relación de alteridad es condición necesaria y fundante de la vigencia de los derechos humanos y en consecuencia de la forma- ción ciudadana. En esta perspectiva Magendzo señala lo que se entiende como educación para la formación ciudadana:

a. La educación para la formación ciudadana está llamada a crear condiciones para aprender a mirar, a escuchar, a sentir a "vigilar" al Otro. Está emplazada a contribuir en la construcción de un lenguaje, una cultura, una conciencia que pregunta sin reparos, sin condiciones, sin búsqueda de reciprocidad: ¿Dónde estás tú? Que no responde con un iacaso yo soy guardián de mi hermano! cuando se le interroga ¿dónde está tu hermano?. Que no contesta acerca del Otro con evasivas, con excusas, con dilaciones. Es enseñar a mirar de frente, aunque esa mirada cause sufrimiento, angustia, impotencia. Enseña a que no se puede dar la espalda y decir "no es asunto mío" aunque no sea asunto mío; o decir "por qué yo... que se preocupen otros, los más cercanos" aunque sea yo el más lejano de los lejanos. La educación ciudadana está llamada a instalar expresiones y comportamientos que dicen: "isí, esto es de mi incumbencia!" y a erradicar del lenguaje y en las acciones, manifestaciones como: "iyo, me mantengo al margen!"

b. La educación ciudadana, es, por definición, una educación para la responsabilidad, es una educación para forjar "vigilantes" alertas del Otro, personas precavidas, atentas del Otro. Pero no por un afán altruista, aunque no estamos descartando el altruismo, no por una pretensión de una humanidad en abstracto, sino una humanidad en concreto, identificada en un sujeto histórico, un sujeto de carne y hueso.

c. Obviamente, que la educación ciudadana descarta toda posibilidad de formar vigilantes para el control con fines de poder. Muy por el contrario, porque la educación ciudadana tiene 
como propósito central formar sujetos de derechos humanos, es decir sujetos empoderados que usan el poder de la argumentación, de la razón, de la confianza para hacer vigente sus derechos y el derecho de los demás, toda pretensión de hacer uso del poder con fines de control, de inspección, de censura, de imposición sería antitética y contraria a la esencia misma de la formación ciudadana. No somos celadores pero si escoltas, no somos policías pero si vigilantes. Somos vigilantes del Otro, porque el Otro nos interpela, nos llama nos hace sujetos.

d. Es verdad, que la educación ciudadana se hace vigilante de todo Otro indistintamente de su origen o procedencia, de su ubicación social o cultural, de su género o etnia, de su edad, de su orientación sexual, de su adscripción religiosa o espiritual. Sin embargo, es más alerta con aquellos grupos que históricamente han visto sus derechos atropellados y violados, su dignidad humillada, su "Rostro" degradado. De esta forma, la educación ciudadana encuentra su ethos éticopolítico en la procura de mayor justicia social, de igualdad de oportunidades, de mayor equidad, de eliminación de las discriminaciones. La responsabilidad es una responsabilidad ética con aquellos que históricamente han sido marginados, excluidos, relegados, estigmatizados, perseguidos.

Es largo el camino por hacer en la educación para la formación ciudadana y la defensa de los derechos humanos desde esta perspectiva. El desafío que queda, pero que es posible formular desde la ética de la alteridad, es cómo se convierte este discurso en una práctica educativa consistente, en especial ahora que existe una marcada tendencia hacia el relativismo, el individualismo y la competitividad. Es una tarea difícil pero no imposible. Hoy, más que antes, hay espacios curriculares que lo exigen y lo permiten, se debe apropiar de esto con proyección.

\section{Conclusiones}

Aquí se formuló la siguiente pregunta de investigación que es la problemática a responder: "¿De qué manera la ética de la alteridad de Lévinas aporta al conocimiento de la formación ética en la educación?". A partir del análisis, interpretación y sistematización de datos e información recogida durante la investigación se pude sacar algunos puntos importantes en relación a la problemática investigada y dar algunas respuestas, claro siempre abiertas y sometidas al debate y a la crítica.

Entonces, ¿Qué aporta realmente la ética de Lévinas a la pedagogía? ¿Por qué se debería tomar como punto de referencia fundamental para la formación ética en la educación? La respuesta es propositiva, se propone la adopción de la ética de la alteridad de Lévinas como elemento importante en el contexto y conocimiento de la formación ética en la educación, tal propuesta se basa en la posibilidad de que esta es la ética que explica mejor el problema de las relaciones humanas.

Un gran reto para la educación y los educadores es utilizar el discurso de la ética de la alteridad en que las acciones deben incluir, es decir, internalizar los principios de relación ética con los demás, dando prioridad a lo propuesto por Lévinas. $Y$ todo comienza por ver el rostro del otro, viendo y escuchando al otro, mirándole a los ojos y ver de cerca su rostro (la alteridad). No es una mirada superficial, es una expresión de empatía, sentir lo que el otro siente, sentir lo que piensa y cómo ve la vida. En resumen, es una ética de la alteridad que establece relaciones de empatía y de inclusión.

El significado y la importancia de la ética de la alteridad en la educación sólo puede ser "aprehendida " cuando se 
"aprehende" el sentido ético del rostro del otro, del diferente, del "totalmente otro". El rostro, como una manifestación del ser humano es paradójico, ya que es a la vez objetividad y subjetividad, tristeza y alegría, angustia y paz, "totalidad e infinito". El rostro es manifestación y misterio; es algo concreto e idealismo a la vez; pero es en el rostro y por el que percibimos y somos percibidos en cuanto seres humanos; el rostro nos aproxima y nos remite a una necesidad ética universal. Es por el rostro que el otro nos impone la necesidad de una "alter conciencia" que de ninguna manera subyuga o anula la autoconciencia. Esa "alter conciencia" (consciencia del otro) impone la ética de la alteridad como filosofía primera, y que presupone una relación o interrelación orientada por el principio del diálogo y de la reverencia hacia el otro. La ética de la alteridad condena la segregación, la exclusión, los prejuicios , y contempla la acogida del Otro, la solidaridad, la diversidad y la justicia, no sólo como una diatriba, sino como una actitud de compromiso moral con el diferente, incluyendo en esta clasificación a nosotros mismos, y por lo tanto con el "totalmente otro".

Es una ética de la alteridad empática. Con que autoridad un profesor o educador puede establecer un juicio de valor y definir lo que es y lo que no es. Si su discurso estuviera basado en una ética reduccionista, ciertamente su práctica pedagógica de la enseñanza y del aprendizaje será excluyente del diferente. Ahora, si su discurso tuviera como parámetro una epistemología de la ética de la alteridad, su práctica pedagógica será liberadora de los estereotipos, prejuicios, preconceptos y exclusión del diferente, pues su práctica será cara a cara, ojo a ojo, teniendo como resultado el respeto por el otro como ser humano único y especial. Para tanto, tal vez sea necesario quebrar paradigmas ultrapasados, quebrar el propio conocimiento construido de manera fragmentada y formateado para no ver el rostro del otro. Si eso fuera necesario, será necesario al mismo tiempo, alimentar el espíritu con nuevos paradigmas con fundamento teórico y epistemológico a favor de la ética de la alteridad. Para eso, es esencial y sumamente necesario tener humildad.

De lo dicho, se puede concluir junto con Pedro Ortega Ruiz que:

a. No se puede educar sin amar porque quien sólo se busca a sí mismo o se centra en su yo, es incapaz de alumbrar una nueva existencia.

b. El educador es un amante apasionado de la vida que busca en los educandos la pluralidad de formas singulares en las que ésta se puede construir.

c. El educador es un escrutador incesante de la originalidad, de todo aquello que puede liberar al educando de la conformación al pensamiento único.

d. Educar es ayudar a inventar o crear modos "originales" de realización de la existencia, dentro del espacio de una cultura, no la repetición o clonación de modelos preestablecidos que han de ser miméticamente reproducidos y que sólo sirven a intereses inconfesables.

e. Educar es ayudar al nacimiento de algo nuevo, singular, a la vez que continuación de una tradición que ha de ser necesariamente reinterpretada. (Ortega Ruiz).

\section{Algunas recomendaciones}

El trabajo tiene un enfoque teórico, y corre el riesgo de no transcender como una propuesta investigativa novedosa que impacte y transforme un contexto educativo. Por eso se reconoce la necesidad de completar este trabajo con la captación de información desde el campo educativo con percepciones de docentes y estudiantes. Es pertinente, entonces, 
aplicar unos instrumentos como encuestas, entrevistas, entre otros de donde se pueda inferir cierta información.

En base a la teoría y propósitos expuestos en este trabajo se recomienda realizar una propuesta pedagógica de formación dirigida a los docentes en la cual se pueda involucrar la ética de la alteridad en el ser y quehacer docente, dado que muchos docentes y diseños de programas no tienen noción de Lévinas, y mucho menos de su propuesta.

\section{Referencias}

Álvarez, A. H., Niño, F. M. (2010). Guía de Investigación. Bogotá: USTA.

Amoraga, F. Entrevista sobre la filosofía de Lévinas. Recuperado el 21 de junio de 2011. Disponible en: http://www.aulas.ulpgc.es/aleman/documentos/ EntrevistaaFrancisco Amoraga. pdf

Bárcena, F., Méllich, J.C. (2000). La educación como acontecimiento ético. Natalidad, narración y hospitalidad. Barcelona: Paidos.

Costa S., L. (2007). O sujeito é de sangue y carne: a sensibilidade como paradigma ético em Emmanuel Levinas. Tesis de doctorado. Rio Grande del Sur: Pontificia Universidad Católica. Recuperado el 18 de noviembre de 2010. Disponible en: http://www. diaadiaeducacao.pr.gov.br/diaadia/diadia/arquivos/ File/conteudo/artigos_teses/FILOSO FIA/Teses/Luciano_ Costa_Santos.pdf

Castelblanco M., J. A. (2009) Hacia otra ética inclusiva del otro excluido: la alternativa levinasiana por lo humano. Trabajo de grado. Bogotá: Pontificia Universidad Javeriana. Recuperado el 23 de mayo de 2011. Disponible en: http://www. javeriana.edu.co/ biblos/tesis/filosofia/tesis48.pdf

García, M. Ética filosófica de Emmanuel Lévinas en obra Totalidad e infinito. Recuperado el 23 de mayo de 2011. Disponible en: http://www.monografias.com /traba jos81/etica-filosofica-emmanuel-levinas-obratotalidad-e-infinito/etica-filosofica-emmanuel-levinasobra-totalidad-e-infinito.shtml.
Lévinas, E. (2003). De otro modo que ser o más allá de la esencia. 4ed. Salamanca: Sígueme.

Lévinas, E. (2004) Difícil libertad. Ensayos sobre el judaísmo. 1a ed. Buenos Aires: Lilmod.

Lévinas, E. (2006). Totalidad e Infinito. 7ed. Salamanca: Sígueme.

Magendzo, A. Alteridad, componente fundante de una educación ciudadana. Recuperado el 23 de mayo del 2011. Disponible en: http://www. colombiaaprende.edu. co/html/investigadores/1609/ fo-article-72543.pdf

Martos, A. A. ed. (2008). Emmanuel Lévinas, la filosofía como ética. Valencia: Universitat de València.

Morin, E. (1999).Los siete saberes necesarios para la educación del futuro. Paris: UNESCO. Recuperado el 23 de septiembre del 2010. Disponible en: http:// www.unmsm. edu.pe/occaa/articulos/ saberes7.pdf

Nava O., J. La comprensión hermenéutica en la investigación educativa. Disponible en: http:// investigacioneducativa .idoneos.com/index. $\mathrm{php} / 349683$

Orozco, S., L. E. (2002). Responsabilidad del docente en la Formación Integral. Bogotá: USTA.

Ortega R., P. La educación Moral como pedagogía de la Alteridad. Recuperado el 01 de junio de 2011. Disponible en: http://www.mercaba.org/ ARTICULOS/E/Ia_educacion _moral_como_ pedagogi.htm

Pérez T., J. A. (2007). Del bienestar a la justicia, aportaciones para una ciudadanía intercultural. Madrid.

Riatiga M., J. (2008). El reconocimiento de la alteridad como apertura hacia el otro en la experiencia humana del conflicto, según Emmanuel Lévinas. Trabajo de grado. Bucaramanga: UIS.

Rodríguez C., I. (2005). Investigación documental. México: Trillas.

Schemes, J. A ética da alteridade na educacao. Recuperado el 18 de febrero de 2011. Disponible en: http:// filosofiaefilosofiadaeducacao.blogspot. com/2007/07/tica-da-alteri dade-na-educao-clique. html

Vieira R., T. (2007). A categoría da alteridade: uma análise da obra Totalidade e Infinito, de Emmanuel Lévinas. Tesis de maestría. Rio Grande del Sur: Pontificia Universidad Católica. Recuperado el 17 de septiembre de 2010. Disponible en: http://www. dominiopublico.gov.br/download/texto/cp033085.pdf 